Religion and Politics in the First Reign and Regency: the Role of Politician-Priests in the Formation of the Brazilian Imperial State

\title{
Religião e Política no Primeiro Reinado e Regências: a atuação dos padres- políticos no contexto de formação do Estado imperial brasileiro
}

\section{Françoise Jean de Oliveira Souza}

Doutoranda em história pela Universidade do Estado do Rio de Janeiro

\section{Resumo}

A pesquisa sobre a qual me debruço tem como fim analisar a atuação política do clero brasileiro no momento inicial de formação do Estado nacional, demonstrando como os chamados "padres-políticos" estabeleceram diálogos com os acontecimentos da época. Neste sentido, pretendese, a partir da realização de uma prosopografia dos padres parlamentares, analisar a conformação desse peculiar segmento da elite brasileira e analisar as discussões levadas por estes à tribuna do poder legislativo, fornecendo, assim, uma pequena contribuição para o estudo da história do pensamento político brasileiro e do processo de formação do nosso Estado. 0 estudo abrange os anos que vão de 1822 a 1842. Esta escolha justifica-se por ter sido este período marcado, sobretudo, pelas discussões em torno da definição das linhas mestras da nova ordem que se formava, além de corresponder aos anos do regime monárquico em que a presença de sacerdotes no parlamento brasileiro fez-se maior e mais significativa.

\section{Abstract}

This research aims to analyse the political actuation of the Brazilian clergy in the early times of the Imperial Estate, showing the connection of those called priests-politicians to some events occurred during the period on focus. In this way, through a collective biography study of priests parliamentarians, this paper will analyse this peculiar sect of the Brazilian politician elite as well as their speeches raised in the parliament. This paper intends to be a contribution to the history of the Brazilian political thought and the formation of the Estate, from 1822 to 1842. The period studied was determined by the fact that this was the time when the debate about the new order was intensified, and also because these were the years during the monarchical era in with the highest proportions of priests in the parliament were observed.

\section{Palavras-chave}

Império do Brasil, religião, poder legislativo

\section{Keywords}

Brazilian Empire, religion, legislative power 
Brasil, Congresso. Câmara dos Deputados. Centro de Documentação e Informação. 0 Clero no parlamento Brasileiro. Brasília: Rio de Janeiro, Fundação Casa de Rui Barbosa, 1978, vol.1 a 5.
Os anos transcorridos entre a emancipação politica do Brasil e o término da experiência regencial caracterizaram-se, sobretudo, pelo processo de construção do Estado Nacional brasileiro. Naturalmente, esse processo trouxe consigo uma série de embates entre correntes de pensamentos e segmentos sociais que, pela primeira vez, assumiam a dianteira da política brasileira.

Um desses setores da sociedade que se fez fortemente presente nos debates políticos de então, assumindo relevante papel no processo de construção das bases do Estado imperial foi o clero. A estes religiosos que ganharam destaque na nossa história política, chamaremos aqui de padrespolíticos.

No início do período monárquico, a presença de padres-políticos fez-se marcante na nossa história, compondo parte da elite política imperial. Dos 102 deputados gerais eleitos para a primeira legislatura brasileira, iniciada em 1826, 23 eram clérigos, representando 22,5\% do total de cadeiras. Na segunda legislatura (1830-1833), os padres-políticos corresponderam a $22 \%$ dos deputados gerais; na terceira legislatura (1834-1837), 24\% e na quarta legislatura (1838-1841)16\%1. A partir daí, sua presença na Câmara dos Deputados tornou-se cada vez menos significativa. Fato similar pôde ser constatado no Senado para onde 13 padres foram eleitos entre 1826 e 1841 , ao passo que, durante todo o Segundo Reinado, somente 4 padres conseguiram ascender a tão alto cargo político.

A considerável presença de elementos da igreja na política brasileira encontra várias explicações. A primeira vem da própria herança deixada ao Brasil pelos anos de dominação colonial. Nestes, em função da atrofia da estrutura burocrático-administrativa do Estado português na sua colônia americana, a autoridade religiosa fez-se mais presente junto à população local, principalmente do interior, comparativamente à presença da autoridade civil laica. Onde houvesse um ajuntamento de pessoas, erigia-se uma igreja. Aliás, a origem de grande parte dos povoados brasileiros dava-se em torno de um templo religioso, o que fazia da Igreja a primeira representante do poder público a fazer-se presente nas localidades mais distantes. Conseqüentemente, o padre, como uma autoridade capaz de mobilizar a população, acabava por assumir funções que extrapolavam as tarefas de natureza religiosa, ocupando o vazio de autoridade deixado pelo Estado. Mesmo depois da independência, quando a justiça então iniciava sua penetração no interior do país através dos juizes de paz, escrivães e delegados, 0 clero ainda se envolvia com vários problemas de natureza judiciária: resolvia desavenças, testemunhava, controlava o movimento migratório interno anotando os domicilianos nas paróquias, registrava doação, compra e venda de propriedades etc. Também não foram poucos os casos em que, diante da ausência de uma determinada autoridade pública, como, por exemplo, os capitães generais, os bispos acabaram sendo consultados quanto às questões relativas à administração das capitanias.

Outra explicação para a conformação desse peculiar segmento da elite política brasileira reside na preeminência do clero entre os homens cultos do país. Cercado por uma população, em sua maioria, iletrada, o clero brasileiro acabou sendo solicitado a concorrer nas eleições, desde a vereança até as câmaras legislativas provinciais, nacionais e no senado. Vale lembrar a discrepância existente entre o nível educacional dos padres e o da massa de analfabetos que compunha o grosso da população. Não por acaso, em 1853, quando os deputados gerais do Império questionavam o exacerbado envolvimento dos empregados públicos com a política, eles 
3

CARVALHO, José Murilo de. A Construção da Ordem. A Elite Politica Imperial. Brasília: Editora Campus, 1980. p.76.

FALCON, Francisco José Calasãs. A época pombalina: política econômica e monarquia ilustrada. São Paulo: Ática, 1982.

NEVES, Lúcia Maria Bastos Pereira das. Corcundas e Constitucionais. A Cultura Política da Independência (1820-1822). Rio de Janeiro: REVAN:FAPERJ, 2003.

SOUSA, Francisco Belisário de. O Sistema Eleitoral no Império. Brasilia: Senado Federal, 1979. tiveram de admitir que esta situação teve origem no fato de que, por volta de 1822, "seriam apenas a magistratura e o clero as únicas categorias cultas do pais"2. De maneira que, o maior letramento ostentado pelos homens da igreja e a liderança intelectual que acabavam por assumir fazia com que estes se apresentassem, principalmente aos residentes nas regiões mais afastadas e menos urbanizadas do Império, como os mais bem preparados para assumirem cargos de representatividade nacional.

Importante também é o fato de que, em razão do Padroado Régio, os padres terem sido, ao mesmo tempo, servidores da igreja e empregados públicos. $E_{1}$ como bem demonstrou José Murilo de Carvalho, o emprego público foi a ocupação que mais favoreceu e treinou para a tarefa de construção do Estado Imperial na sua fase inicial, isto é, de 1822 a 1850. 0 Estado foi o maior empregador do tipo de gente que foi levada ao poder público, aos cargos eletivos do legislativo e aos cargos do executivo ${ }^{3}$.

Acrescente-se a isto o fato de que um dos grandes efeitos da política pombalina no Brasil foi a formação de religiosos para os quais a atuação política se fizera natural, uma parte da vida eclesiástica. 0 Reformismo ilustrado português, inaugurado durante o governo do marquês de Pombal, foi marcado pela absorção de alguns princípios iluministas que levaram à adoção de uma politica de reformas em questões pontuais, visando evitar o abalo das estruturas vigentes. Os teóricos executores dessa vertente reformista acreditavam que, mais do que nunca, o poder deveria centrar-se no governante, o que tornaria possivel a efetiva promoção do desenvolvimento do Estado. Propugnavam, portanto, a modernização do Estado português sem um rompimento radical com as suas formas tradicionais 4 . De maneira que o iluminismo adotado pela reforma portuguesa foi essencialmente católico e cristão, tendo sido promovido, não por livres pensadores, como o foi na França, mas, por homens "ilustrados" da própria Igreja, particularmente, pelos Oratorianos. Esse fenômeno foi possivel em função do caráter ambíguo do reformismo ibérico, que impôs uma absorção fragmentada e peculiar das luzes, conferindo-Ihe um caráter pragmático. Isto porque o iluminismo mitigado português, do qual o Brasil independente foi herdeiro, não realizou por completo a obra de secularização da política, mas, ao contrário, tomou o clero secular como aliado, colocando-o a seu serviço ${ }^{5}$.

Finalmente, deve-se considerar que a presença de religiosos no parlamento foi potencializada pela própria carta constitucional de 1824 e o decreto de 26 de março do mesmo ano, que atribuíam aos párocos funções importantíssimas no processo de realização dos pleitos. 0 envolvimento dos sacerdotes com o processo eleitoral não só tornava mais natural a associação entre prática religiosa e prática política, como fornecia aos homens da Igreja os instrumentos de controle e manipulação das eleições.

De acordo com as regras vigentes, as eleições gerais e provinciais seriam indiretas, e em dois graus: a massa dos cidadãos votantes de cada paróquia se reuniria na igreja matriz e elegeria os eleitores. Em seguida, nas eleições de segundo grau, os cidadãos eleitores formavam o colégio eleitoral que, reunido nas cidades ou vilas, que eram "cabeças de distrito", elegiam os representantes da província e da nação ${ }^{6}$. Antes do início propriamente dito da eleição, cabia ao pároco afixar os editais de convocação dos votantes nas portas das suas igrejas. No dia marcado para as eleições paroquiais, os cidadãos votantes e eleitores eram reunidos na matriz onde o pároco celebrava uma missa e fazia uma pregação contemplando os objetivos daquela assembléia, o processo eleitoral. Era, portanto, pelas mãos de um sacerdote 
7

BASTOS, Ana Maria Rodrigues. Católicos e Cidadãos. A Igreja e a Legislação Eleitoral no Império. Rio de Janeiro: Lumem Júris, 1997. p.19 e a partir de uma celebração religiosa que se iniciava, oficialmente, o pleito para a escolha dos membros do legislativo brasileiro. De maneira que, estabeleceu-se no nosso sistema eleitoral uma espécie de "simbiose entre o político-administrativo e o religioso, entre o temporal e o clerical, o profano e o sagrado"7. Vale dizer que não havia situação melhor para que o pároco indicasse os candidatos apoiados por ele ou pela Igreja, ou ainda, para se apresentar, ele mesmo, como o melhor candidato.

Contudo, a participação do clero não se limitou à abertura das eleições, tendo se mostrado também importante na aplicação das exigências legais de qualificação dos cidadãos votantes e eleitores. Como o recém formado Estado brasileiro não criara uma estrutura de pessoal e repartições necessárias à verificação da situação dos eleitores e votantes, ele teve que lançar mão da documentação e das informações controladas pela igreja. Somente os registros religiosos que estavam sob a posse do clero possibilitavam ao Estado obter as informações que interessavam para a realização das eleições, ficando a cargo dos párocos elaborar as listas dos eleitores qualificados a votar. Conseqüentemente, os párocos eram designados a participar das mesas eleitorais, esclarecendo as dúvidas de inclusão ou exclusão dos votantes, atuando como árbitro nas contendas das apurações e, conseqüentemente, assumindo um papel definidor dos resultados eleitorais.

Assim, tendo em vista que os limites entre o religioso e o civil eram estreitos no Brasil desde os tempos coloniais, o catolicismo não escapou das aspirações transformadoras que estavam em curso no processo de elaboração dos novos quadros da sociedade após a independência. Diante das novas perspectivas trazidas pelas discussões acerca do modelo de Estado a ser instaurado no Brasil, os padres-políticos eleitos aproveitaram a oportunidade para repensar a situação política da Igreja brasileira, na expectativa de inaugurar uma nova fase de sua história, marcada por uma tentativa de nacionalização da religião católica. Entre o clero, era também unânime a urgente necessidade de reformar a Igreja no que se refere à situação moral de seus membros. Além de insuficiente, mal remunerado e mal distribuido pelas paróquias, o clero brasileiro encontrava-se mal preparado em matéria religiosa e coberto por escândalos morais, colaborando para a heterodoxia do catolicismo no Império.

Todavia, se por um lado era comum a crença na necessidade de reformas, por outro, não havia um consenso acerca da direção a ser seguida por estas e nem por quem elas seriam conduzidas. Um dos maiores embates estabelecidos no seio do clero consistiu em definir se as reformas religiosas diziam respeito exclusivamente à Igreja ou se, ao contrário, deveriam partir e serem dirigidas pelo poder secular. Este embate refletia a própria indefinição acerca do relacionamento que vigoraria entre a velha igreja e o novo Estado que se formava. A grande quantidade de assuntos eclesiásticos discutidos pelo parlamento brasileiro durante o Primeiro Reinado e regências demonstra o tamanho dessa indefinição e o desejo por transformações ${ }^{8}$.

Sem pretender esgotar em esquemas fechados toda a variedade de posicionamentos político-religiosos existentes entre os padres-políticos, pôde-se perceber que, grosso modo, estes se dividiam em dois grupos que, embora não organizados oficialmente, optamos por chamar de "católicos liberais" e de "católicos conservadores". Estes grupos tinham, em padre Antônio Diogo Feijó e em Dom Romualdo Antônio de Seixas, arcebispo da Bahia e Primaz do Brasil, suas respectivas lideranças. 
MONTENEGRO, João Alfredo de Sousa. Evolução do Catolicismo no Brasil. Petrópolis: vozes, 1972.

10

RICCI, Magda. Assombrações de um padre regente. Diogo Antonio Feijó (1784-1843). Campinas: Editora da Unicamp, 2001. p.360.
Na sociedade católica do século XIX, surgiu o que a historiografia nomeou de catolicismo liberal ${ }^{9}$. Esta corrente político-religiosa foi marcada por uma tendência progressista de adaptação da Igreja ao novo universo intelectual e às novas condições sociais que se impunham. Dentro desta perspectiva, os católicos liberais brasileiros pensaram e discutiram as questões eclesiásticas no âmbito do Estado Nacional que se formava. Estes religiosos tinham uma idéia bastante moderna das liberdades da Igreja brasileira em face da Igreja universal, sustentando a competência e a legitimidade da interferência do poder civil para examinar os assuntos constantes nas bulas papais. Deste modo, os católicos liberais estavam convencidos de que as reformas da Igreja deveriam ser levadas a feito pelo governo, uma vez que os interesses da religião se fundiam com os do Estado.

Coube exatamente a estes padres encabeçarem, na Assembléia Geral, os projetos de reforma que buscavam enfraquecer a influência romana sobre a Igreja brasileira, tais como a proposta de extinção das ordens religiosas e a proibição da entrada de frades estrangeiros, uma vez que estes eram considerados como defensores das pretensões teocráticas do papa e, logo, uma ameaça à soberania brasileira. Quanto às questões relativas à organização interna da igreja propunham, além da abolição do celibato clerical, o alargamento da autoridade dos bispos em detrimento da do papa e, por sua vez, a diminuição da autoridade dos bispos em prol de uma maior participação do clero na administração diocesana. Chegam a defender, inclusive, uma política característica de uma "democracia clerical", propondo mecanismos eletivos para a escolha dos clérigos, em detrimento da autoridade dos bispos.

Vale lembrar que em todos os momentos em que as discussões parlamentares resvalaram na questão da soberania nacional, quando, por exemplo, por ocasião dos debates acerca de quem deveria nomear os bispos brasileiros, se o imperador ou o Papa, os sacerdotes liberais, posicionaramse claramente em favor do Estado, baseando-se na idéia explicitada por Feijó de que: "se a nação brasileira não tem a força e o poder necessário para promover sua prosperidade sem o consentimento da Cúria Romana, então não é independente, não é nação"10. Destas palavras de Feijó depreende-se a existência entre o clero liberal do que poderiamos chamar de Jansenismo tardio. 0 Jansenismo correspondeu ao nome dado à tentativa de reforma da Igreja católica desenvolvida na França do século XVII. Dentre seus vários projetos, defendiam o direito do rei de controlar uma Igreja nacional, concedendo o placet e ganhando independência em relação a Roma. Combatiam os jesuítas - considerados os maiores defensores do poder de Roma - e mostravam-se tolerantes para com os protestantes. Poderoso instrumento de afirmação nacional, o Jansenismo ajudou a sociedade moderna a romper com a universalidade atribuida à cristandade e que, até então, favorecia a hegemonia política da Igreja sobre os reinos europeus, bem como inspirou os Estados a uma política agressiva contra a Cúria Romana que, naquele contexto, apresentava-se como uma das grandes ameaças à soberania das monarquias européias.

Seguindo esta linha jansenista, percebe-se o despertar da consciência nacionalista entre o clero brasileiro, sendo esta marcada por uma tônica regalista. 0 sentimento patriótico assumiu uma conotação específica para estes padres, constituindo-se na luta por uma autonomia do Estado com relação à influência exercida pelo Vaticano. Esse jansenismo tardio assumido pelos sacerdotes liberais e que, para os seus opositores, parecia 
RICCl, Magda. Assombrações de um padre regente.Diogo Antonio Feijó (1784-1843). Campinas: Editora da Unicamp, 2001. p.45.

12

ver: ALMEIDA, Luiz Castanho de. O Sacerdote Diogo Antônio Feijó. Rio de Janeiro: Ed. Vozes, 1951. BARBOSA, Francisco de Assis. Sintese Histórica. IN: Brasil, Congresso. Câmara dos Deputados. Centro de Documentação e Informação. O Clero no parlamento Brasileiro. Brasília: Rio de Janeiro, Fundação Casa de Rui Barbosa, 1978. vol 1. MONTENEGRO, João Alfredo de Sousa. Evolução do Catolicismo no Brasil. Petrópolis: vozes, 1972.VIEIRA, David Gueiros. $O$ Protestantismo, a Maçonaria e a Questão Religiosa no Brasil. DF: Editora Universidade de Brasília, 1980.

13

0 termo conservadorismo comporta dois significados. Um primeiro, mais amplo, refere-se a um fenômeno mais ou menos universal, que pode ser entendido, também, como tradicionalismo, ou seja, a tendência a apegar-se a padrões e modos de vida já consolidados, antigos. 0 tradicionalismo pode ser considerado, portanto, como uma reação a deliberadas tentativas de reforma. 0 segundo significado - que é o utilizado no presente texto - refere-se a um fenômeno político claramente moderno, produzido por circunstâncias históricas específicas. Para melhor compreensão do termo conservadorismo, ver: MANNHEIM, Karl. 0 Significado do Conservadorismo IN: Karl Manheim: Sociologia. Organizadora: Marialice Mencarini Foracchi. São Paulo: Atica, 1982.

14

SILVA, Francisco Carlos Teixeira da. Dicionário Critico do Pensamento da Direita. Rio de Janeiro: FAPERJ/Mauad, 2000.

15

LUSTOSA, Oscar de Figueiredo. Reformismo na Igreja do Brasil império. SP: USP. Boletim n 17, 1977. um contra-senso, era encarado por Feijó como algo natural, afinal, como demonstram suas palavras, "ser católico não era ser servil a Roma, mas discutir a disciplina eclesiástica no âmbito do Estado Nacional" 11.

Não foram somente os opositores contemporâneos aos padres liberais que demonstraram estranhamento frente às suas atitudes políticas. A historiografia da igreja, e, particularmente, os estudos voltados para os padres que se destacaram politicamente, consolidaram a crença de que os sacerdotes do início do XIX foram homens religiosamente equivocados e que, de tão envolvidos com as questões seculares, acabaram por negligenciar seus deveres espirituais ${ }^{12}$. Em geral, estes padres são tomados como homens que optaram por abandonar a vida religiosa e a fé católica em favor de suas carreiras políticas. Politicamente, eles são descritos como subservientes ao governo em troca de cargos públicos, aceitando sem questionamento as investidas do Estado contra os tradicionais privilégios da Igreja. Nesta linha de raciocínio, o posicionamento político-religioso do clero liberal, encontraria explicação, não em seus princípios teológicos e filosóficos, mas, principalmente, em seus interesses políticos e econômicos pessoais.

É preciso, porém, romper com estas impressões que tendem a desconsiderar a convicção religiosa desses homens, levando em conta, exclusivamente, o seu lado político. Naquele contexto histórico, não havia uma clara cisão entre o mundo da política e da religião, ao contrário, os homens daquela época tinham uma forma muito própria de juntar os dois universos, uma vez que o terreno da moral e da religião era tido como de interesse público. Do mesmo modo, o serviço público era entendido claramente como uma forma de servir à Deus e à Igreja. Esta estranha simbiose fica clara quando, por exemplo, Feijó apresentou o projeto de Constituição Eclesiástica por ele elaborado, como uma natural continuidade das reformas inauguradas com a Constituição civil do Império. Portanto, a dedicação desses sacerdotes à política não pode ser entendida como uma conseqüente morte do homem religioso. Ao contrário, o entendimento das motivações que moviam os padres-políticos em suas batalhas públicas exige que estas sejam analisadas a partir de características que Ihes são muito próprias, isto é, como fruto de uma elite política e religiosa que, embora muito próxima do Estado, não se prendia unicamente aos interesses deste, mas que, ao contrário, tinha sua compreensão do mundo e da política pautadas, dentre outras coisas, por suas convicções religiosas.

Em contraposição ao círculo liberal, havia na Igreja brasileira um segmento conservador. 0 conservadorismo ${ }^{13}$ foi um pensamento desenvolvido na Europa moderna como tentativa dos setores mais abalados pela Revolução Francesa de deter o processo desintegrador dos antigos valores. Esta corrente de pensamento fundamentou inúmeros e importantes projetos político-ideológicos do século XIX e XX. Em pleno século da ciência e do progresso, o conservadorismo defendeu, em linhas gerais, a descrença na razão, a compreensão dos direitos como determinados pela tradição e não como dados naturais, a idéia da subordinação das relações sociais ao principio da ordem e disciplina, a negação do individualismo em prol do coletivo, a crença na infalibilidade do Papa e a importância do mistério e do obscuro como base da vida social e política ${ }^{14}$.

Os católicos conservadores do Brasil, em consonância com o conservadorismo europeu, caracterizaram-se pela defesa do ultramontanismo, voltados para a Santa Sé na linha da centralização papal15. Dentro deste grupo, Dom Romualdo Antônio de Seixas emergiu como figura proeminente 
16

Esforço de aproximação da pratica católica com as diretrizes romanas, buscando o estabelecimento de uma maior ortodoxia católica.

17

VILLAÇA, Antônio Carlos. O Pensamento Católico no Brasil. Rio de Janeio: Zahar editores, 1975. p.10.

18

PAIVA, Gilberto. Meados do século XIX: A Igreja no Brasil toma novos rumos. IN: Fragmentos de Cultura. Instituto de Filosofia e teologia de Goiás. Goiânia, V.9, n³, p.543, maio-junho, 1999. do movimento de reforma católica que, na direção contrária ao proposto pela reforma dos liberais, visava a regeneração da Igreja segundo os moldes tridentinos. Isto quer dizer que muito embora não questionasse o direito do padroado régio, este segmento conservador impunha sérias restrições à interferência do Estado em assuntos da Igreja. Também, lutando pela criação de mais seminários no Brasil e adequando-os às diretrizes romanas, os católicos conservadores visavam, elevar o nível educacional do clero para que fosse possivel corrigir as distorções existentes entre a prática católica e as doutrinas da religião, buscando uma maior ortodoxia. Também defendiam a presença das ordens religiosas no Brasil, uma vez que estas eram consideradas por eles como importantes guardiãs dos valores ortodoxos católicos e importantes combatentes dos inimigos da verdade divina, tais como os protestantes, os deistas, os maçons, os cientistas e os liberais; ou seja, todos aqueles que depositaram sua fé na razão individual.

Dom Romualdo e seu séqüito de conservadores foram os que mais se interpuseram aos projetos reformistas que Feijó e seu grupo apresentavam na Assembléia Geral. Neste contexto, este grupo de padres políticos vislumbrou uma Igreja mais autônoma (mas não um Estado laico), questionou as atitudes do Estado (ainda que muitos deles possuissem cargos dentro desse mesmo Estado), e lançou as primeiras sementes daquilo que mais tarde viria a ser a tão falada Questão Religiosa e a romanização ${ }^{16}$ da Igreja brasileira.

Cabe aqui uma pausa para uma breve, porém, importante, observação. Apesar da destacada atuação do segmento conservador da igreja dentro do parlamento, a historiografia do Império pouco reconheceu a importância desses religiosos para a formação do pensamento católico brasileiro. Negligenciando a existência de um grupo de católicos conservadores, ainda no início do século XIX brasileiro, a historiografia tendeu a focar os estudos relativos a crise entre Igreja e Estado apenas nos conflitos de 1872 e nos clérigos nele envolvidos, criando a falsa impressão de que, até então, as relações entre os dois poderes havia se dado sem maiores embates. Segundo o estudioso da igreja, é somente na década de 1870-80 que se processa o começo da reação católica contra a ingerência do Estado. Nas palavras de Antônio Carlos Villaça, renomado historiador do catolicismo brasileiro "....se quiséssemos escolher uma data e uma figura, escolheriamos a figura de Dom Vital e a data de 1873, isto é, a Questão Religiosa. É a primeira afirmação antipombalina - católica - da história espiritual do Brasil". ${ }^{17}$ Conseqüentemente, os conflitos religiosos dos anos 20 a 40 do Império, num dos "periodos de maior exaltação dos ânimos entre pensadores, clero e autoridades do Brasil"18 não mereceram a quantidade de estudos condizente com sua importância histórica.

Extrapolando o universo da Assembléia Geral e da Corte, o conservadorismo católico manifestou-se também, ainda que de forma heterodoxa, entre segmentos mais simples da população e do clero brasileiro. A Cabanada (1832-1836), por exemplo, movimento ocorrido no agreste de Pernambuco e Alagoas, foi marcada pela presença de discursos e objetivos declaradamente conservadores e absolutistas. Desfavoráveis à abdicação de Dom Pedro I e críticos mordazes das investidas do Estado contra a Igreja e Roma, denunciavam:

0 benéfico e amante pai dos brasileiros espoliado! A religião santa de nosso Senhor Jesus Cristo deprimida e vilipendiada! (...) Os religiosos, esses sustentáculos da disciplina da mesma religião, esbulhados e insultados! A casa da mãe de Deus convertida em sinagoga de Pedreiros livres. ${ }^{19}$
FREITAS, Décio. Os Guerrilheiros do Imperador. Rio de Janeiro: Graal, 1978. p.85. 
20

MENCK, José Theodoro Mascarenhas. 0 Parlamento Imperial, a Liberdade religiosa e as relações Estado-Igreja no Brasil (18231889). Dissertação de mestrado. Univesidade de Brasília, Brasília, 1995

21

ROMANO, Roberto. Brasil: Igreja contra Estado (Critica ao populismo católico). São Paulo: Kairos, 1979. p.7.
0 discurso citado permite perceber que catolicismo e monarquia permaneciam ainda muito vinculados no imaginário social brasileiro. Principalmente nas regiões rurais, religião e monarquia conviviam de mãos dadas, numa aura de misticismo popular. Se pensarmos que durante o primeiro reinado e regências, o Brasil carecia de uma autêntica e difundida idéia de nação, o catolicismo emerge como um importante elo entre os membros do corpo social que se queria fundar, fornecendo sustentação à identidade e unidade nacional e à perspectiva de lealdade indispensável à ação do Estado. Desse modo, a manutenção de uma política agressiva em relação a Roma poderia não parecer uma boa estratégia diante da iminência de fragmentação do Império.

Esta talvez seja a explicação para o fato de que os projetos mais polêmicos defendidos pelos católicos liberais nunca chegaram a serem aprovados pela Assembléia Geral ${ }^{20}$. De qualquer forma, a visão liberalizante e jansenista deste grupo deu o tom do relacionamento estabelecido entre a Igreja e o Estado brasileiro ao longo de todo o período monárquico. Dom Romualdo, por outro lado, se não conseguiu, ainda na primeira metade do século XIX, impor seu modelo de igreja reformada ao sabor tridentino, acabou por lançar o germe daquela que seria uma das mais importantes reformas pela qual passaria a igreja brasileira, reforma esta iniciada em meados do Segundo Reinado e consubstanciada na República. Seu discurso conservador, aliás, ajuda-nos a conhecer uma série de imagens e conceitos que colaboraram para a justificação do poder do Estado conservador implantado nos anos 30 do século XX. Segundo Roberto Romano, a aproximação da rede discursiva conservadora, presente desde o século $X I X$, das experiências políticas do século XX, permite-nos ver "o quanto certas idéias recentes lançaram raizes nos séculos passados, visando harmonizar razão e sentimento, orientando as manifestações teológico-politicas ou secularizantes que disputam até hoje a condução da nossa vida política"21.

A atuação do clero na política brasileira não se restringiu, contudo, aos debates religiosos. Ao contrário, ao longo dos vinte anos aqui estudados, os padres-políticos estiveram envolvidos nos principais acontecimentos da nossa história parlamentar: da constituinte de 1823, passando pela tentativa de instauração de uma nova Assembléia Constituinte em 1832, também conhecida como a "revolução dos Três Padres", à aprovação do Ato Adicional de 1834 até o golpe da maioridade. Até o momento em que nos encontramos com a pesquisa, não foi possivel ainda mapear de que maneira o clero se organizou dentro da embrionária estrutura político-partidária que começava a se formar. Ainda não sabemos também se os padres que compuseram o círculo liberal e o conservador mantiveram-se coesos quando os assuntos tratados no parlamento eram de caráter estritamente secular. Estas questões ainda estão por serem estudadas na pesquisa sobre a qual nos debruçamos. De qualquer maneira, já foi possivel perceber que houve uma tendência de aproximação dos padres ao grupo político tradicionalmente chamado pela historiografia de liberais moderados. Isto, entretanto, não nos permite afirmar que o clero assumiu um posicionamento político homogêneo a ponto de se constituir numa "bancada clerical" dentro da Assembléia Geral. Ao contrário, entre os 84 padres eleitos no Primeiro Reinado e nas Regências, encontramos tendências políticas as mais diversas: de exaltados como o padre Marcelino Pinto Ribeiro Duarte, passando por liberais moderados como Feijó e seu séqüito, até conservadores como o 
22

CARVALHO, José Murilo de. A Construção da Ordem. A Elite Política Imperial. Brasilia: Editora Campus, 1980. p.151

23

Ibidem, p.44.

LUSTOSA, Isabel. Insultos Impressos. A Guerra dos Jornalistas na Independência (1821-1823). São Paulo: Companhia das Letras, 2000. p.71. padre Francisco Ferreira Barreto. Houve também aqueles como o pernambucano Venâncio Henrique de Resende que, à maneira de Bernardo Pereira de Vasconcelos e ao gosto da cultura política brasileira, caminhou de um extremo ao outro, ao sair dos campos de batalha da Revolução Pernambucana de 1817 e da Confederação do Equador para assumir as fileiras do futuro Partido Conservador.

Importante destacar que padres do Império não tiveram sua prática política limitada aos espaços oficiais de poder vinculados ao Estado. Ao contrário, com o intuito de verem concretizados seus modelos de reforma religiosa, bem como, seus projetos políticos seculares, eles travaram suas batalhas políticas em muitos outros espaços, como no front das revoluções, na imprensa e nos diversos clubes associativos surgidos no período em questão.

É de conhecimento de todos o fato de muitos padres terem participado de revoluções ao longo da primeira metade do século XIX. Em um primeiro momento poder-se-ia pensar que esses padres revolucionários eram compostos somente por membros do baixo clero ou oriundos de segmentos sociais mais baixos, o que thes tornariam líderes populares em potencial. Contudo, ao contrário disto, muitos foram os padres da alta política do império, como os membros da Assembléia Geral aqui estudados, que participaram destas revoluções. Do total dos padres-políticos pertencentes à Assembléia Geral, 29\% participaram de alguma revolução, tendo sido presos e alguns exilados. Também José Murilo de Carvalho afirma que grande parte dos padres revolucionários era de origem rica. Muitos se envolveriam em revoluções por assumirem um liberalismo mais próximo ao dos fazendeiros, isto é, que se opõe à interferência do governo central em seus domínios 22 . Importante lembrar que, após sofrerem as repressões por parte do governo imperial, a quase totalidade desses padres revolucionários, no melhor exemplo da nossa cultura política da conciliação, reassumiu cargos representativos ou postos importantes dentro da estrutura política do Estado.

Importante também foi a atuação dos padres-políticos na imprensa. Esta atividade, aliás, acabou por configurar-se como uma extensão de suas atividades parlamentares, na medida que a imprensa tornou-se "um foro alternativo para a tribuna", onde se diziam coisas que não se ousava dizer na tribuna da Câmara ou do Senado23, além de traduzir para um público leitor mais amplo o que ocorria em ambientes restritos, como o da Assembléia Geral. A partir das informações que foram levantadas até então, é possivel afirmar que, no mínimo, 27\% dos padres que tiveram assento no parlamento atuaram intensamente na imprensa, editando ou redigindo importantes periódicos brasileiros. Não foram poucos os padres políticos responsáveis por levar a imprensa às regiões mais distantes das províncias das quais se originavam. Também Isabel Lustosa, analisando a imprensa brasileira no início do XIX, percebe a presença constante de padres na redação de jornais, fenômeno este atribuído, em parte, à falta de profissionalização do jornalismo brasileiro. Analisando, por exemplo, a redação do Gazeta do Rio de Janeiro, editada por funcionários públicos e sacerdotes, a autora afirma que esta era "uma mistura de redação propriamente dita com repartição pública e claustro"24. 0 significativo envolvimento dos padres-políticos com atividade da imprensa, além de reforçar seu desejo de participação política por meios outros que não somente os cargos eletivos, 
ampliando o modo pelo qual interagiam com o mundo secular e faziam política, demonstra que esse segmento da elite política e religiosa brasileira compunha, também, parte da nossa elite intelectual.

Esta última constatação é corroborada pela presença de 44\% de padres-políticos em 24 diferentes espaços de sociabilidade que surgiam no Brasil, e, em particular, no período regencial. Este último é marcado por diversas manifestações de surto associacionistas em decorrência da inquietação política, social e econômica gerada pela abdicação do imperador. Sociedades politicas, filantrópicas e culturais como a Defensora da Liberdade e da Independência Nacional, Sociedade Auxiliadora da Indústria Nacional, Sociedade Coluna do Trono e do Altar, as maçonarias e sociedades secretas, o Instituto Histórico e Geográfico Brasileiro contaram com a significativa presença e liderança do clero brasileiro. Muito embora alguns desses espaços associativos não se apresentem explicitamente como detentores de objetivos políticos, como por exemplo, o IHGB, há, sem sombra de dúvidas, um caráter político subjacente a todos eles, uma vez que permitiam a aproximação estratégica entre os membros da elite política brasileira. A política, é importante lembrar, de maneira nenhum constitui um fenômeno restrito ao Estado, ao contrário, mostra-se presente em relações desenvolvidas em várias instâncias sociais. Assim, no caso particular do clero, é possivel inferir que sua presença em tais meios significava a maior possibilidade de articulação política e desenvolvimento de contatos estratégicos capazes de lhes garantir, não só a efetivação de seus projetos políticoreligiosos, como também a ascensão a altos cargos eclesiásticos.

0 momento áureo da ação política do clero no parlamento e nos demais espaços de atuação política aqui apresentados foi se desfazendo a partir do Segundo Reinado. Enquanto os clérigos assumiram papeis de destaque na política brasileira ao longo das quatro primeiras legislaturas que cobrem o Primeiro Reinado e Regências, a partir de 1841 eles foram ocupando cada vez menos cadeiras no parlamento. Conseqüentemente, sua atuação na Assembléia Geral foi tornando-se apagada, com raros e pálidos discursos incapazes de inflamar o espírito de seus companheiros do legislativo, como se dera outrora.

Este fenômeno é conseqüência de vários fatores, dos quais destacamos três: o primeiro diz respeito ao próprio perfil da elite política brasileira que vai se transformando, a partir de 1870, quando os funcionários públicos perdem espaço no parlamento para os bacharéis e fazendeiros.

0 segundo fator vincula-se às várias reformas eleitorais ocorridas ao longo do império e que afastaram, gradativamente, o clero das funções eleitorais, sendo substituídos por um corpo de funcionários civis laicos nomeados diretamente pelo Estado para desempenhar não só as tradicionais atividades exercidas pela Igreja na área eleitoral, como também as funções cartoriais: registro civil, casamento, óbitos, registros de imóveis etc. Ao se comparar as alterações na legislação eleitoral com os dados quantitativos referentes ao número de cadeiras ocupadas pelo clero no parlamento brasileiro, ao longo do século XIX, fica claro que o maior ou menor controle do processo eleitoral por parte do clero significou, em certa medida, maior ou menor possibilidade de vitória dos sacerdotes nas eleições gerais.

0 último fator de explicação passa por questões internas à igreja católica. Ao longo do século XIX, foi ocorrendo uma progressiva inversão dos valores religiosos predominantes no interior do clero brasileiro. Os conservadores que, a princípio, encontravam-se em minoria, foram 
25

MATA, Sérgio da. "JUC e MMC: polaridade politico-religiosa em Belo Horizonte". Revista de História Regional. Vol 3. N 1, 1998. ganhando força dentro da Igreja no Brasil, acompanhando o movimento internacional de Romanização das Igrejas católicas, encabeçado pelo papa Pio IX. Como conseqüência, tem-se o progressivo afastamento dos padres dos espaços oficiais de poder do Estado. 0 clero, agora, volta-se para as questões internas da Igreja, para o fortalecimento da instituição, para a melhor formação de seus membros, e, principalmente, para a luta em prol da ortodoxia católica. Envolvendo-se menos com as questões políticas seculares, embora nunca as tenham abandonado completamente, o clero brasileiro foi, cada fez mais, afastando-se da tribuna parlamentar e assumindo o púlpito, os seminários e a catequese como o lugar, por excelência, de sua manifestação pública. Realizando uma sublimação da política, a partir de um relativo afastamento do "mundo", o conservadorismo católico conseguiu uma erradicação quase que total da figura do padre político que foi, nas palavras de Dom Antônio Ferreira Viçoso, sétimo bispo de Mariana, a "grande peste do rebanho" que, por muito tempo, contaminou e enfraqueceu o corpo da Igreja 25 . 